\title{
Levodopa and Huntington's chorea
}

\author{
C. LOEB, ${ }^{1}$ G. ROCCATAGliatA, G. LA MEDiCA, G. ABbRUZZESE, \\ AND C. ALBANO
}

From the Department of Nervous and Mental Diseases, University of Genoa, and Central Laboratory of Institute G. Gaslini, Genoa, Italy

SYNOPSIS Two patients with Huntington's chorea are reported whose psychiatric and neurological symptoms greatly improved after treatment with L-dopa. In both cases the basal values of CSF HVA were markedly decreased, being increased by the treatment with L-dopa.

The so-called clinical opposition between Parkinson's disease and Huntington's chorea has its pharmacological and biochemical counterparts. Choreic movements are improved by a variety of agents that deplete the brain of monoamines or interfere with dopamine at the receptor sites (for references see Barbeau, 1973).

On the contrary, treatment with L-dopa, regarded, as is well known, as a dopamine (DA) replacement therapy ('specific though probably predominantly symptomatic', Bernheimer et al., 1973), markedly increases the choreic movements of Huntington's disease and, when used in patients with Parkinsonism at high doses or for a prolonged period of time, may cause the appearance of a variety of abnormal movements (Barbeau, 1969; Cotzias et al., 1969; Klawans and Garvin, 1969; Barbeau et al., 1971).

Recent determinations of dopamine catabolites in CSF showed normal or low-normal values of homovanillic acid (HVA) in Huntington's chorea and diminished levels of HVA in Parkinson's disease (Bernheimer et al., 1966; Hornykiewicz, 1966; Birkmayer, 1969; Klawans, 1971; Guilleminault et al., 1973; Loeb et al., in press). After a probenecid test HVA levels were similar to controls (Aquilonius and Sjöström, 1971; Lal et al., 1973) or about half that of control subjects (Chase, 1973).

Levels of 5-hydroxyindoleacetic acid (5-HIAA) (serotonin metabolite) and 3-methoxy-4-hydroxy-

'Address for correspondence: Professor C. Loeb, Clinica Malattie Nervose e Mentali dell'Università, Via De Toni, 5-16132 Genoa, Italy.

(Accepted 29 April 1976.) phenylglycol (MHPG) (noradrenaline metabolite) were not found to be significantly varied in Huntington's chorea. Moreover, studies on cerebral dopamine metabolism showed a decrease of DA and HVA in the striatum and the pallidum in Parkinson's disease, while no significant reduction of these metabolites was found in Huntington's disease, except in the caudate nucleus, so that a possible putaminal dopaminergic predominance has been suggested (Bernheimer et al., 1973).

These findings in Huntington's disease seem to have the following exceptions:

1. A substantial diminution of HVA concentration in the cerebrospinal fluid, suggesting a reduction in dopamine metabolism, has been reported (Curzon et al., 1972; Chase, 1973), even if no apparent correlation between HVA decrease and the severity of motor abnormalities could be established.

2. A few cases, some with lower levels of CSF HVA, associated with a good responsiveness to treatment with L-dopa, have been described by some authors (Tan et al., 1972; Schenk and Leijnse-Ybema, 1974).

We present two additional cases of Huntington's chorea with reduction of the CSF content in HVA, both of which were improved by treatment with L-dopa.

\section{METHODS}

Two unrelated female patients (case 1 and 2) with Huntington's chorea and a positive family history 
involving two successive generations were studied (Figure). The disease, which had begun six and five years previously, showed at the onset only psychiatric disturbances, consisting of a paranoid reaction (case 1; C.A.) and a catatonic-like picture (case 2; V.I.); when referred for neurological examination they showed severe mental deterioration (Table 1) and such marked and diffuse choreic movements that speaking, walking, and feeding were rendered almost impossible.

The patients were kept untreated and on a constant diet for 15 days; lumbar punctures were performed at 9 a.m. with the patient on her side, after having been fasted and confined to bed during the preceding 12 hours; levels of HVA, 5-HIAA, and MHPG were determined fluorometrically, according to the methods of Korf et al. $(1969,1971 \mathrm{a}, \mathrm{b})$ on the first $8 \mathrm{ml}$ of CSF.

During the next 10 days, phenothiazine derivatives were administered according to the following schedule: fluphenazine, $100 \mathrm{mg}$ daily in case 1; perphenazine $40 \mathrm{mg}$ daily in case 2 . At the end of this period, while the patients showed no clinical changes, a second lumbar puncture was performed in the same way as before. After a 15 day period of rest without treatment, L-dopa ( $2 \mathrm{~g} /$ day $)$ was administered; at the end of 15 days' treatment with levodopa a third lumbar puncture was carried out.

\section{RESULTS}

The CSF HVA values of our two patients with Huntington's chorea were at the lower end of the range as compared with controls and the values reported in the literature for chorea major (Table 2; see, however, Chase, 1973).

Phenothiazine therapy proved unsuccessful for both psychiatric and choreic symptoms which, sometimes, appeared to become worse. Moreover, it did not produce significant variations in CSF HVA (Table 2). On the contrary, L-dopa, at dose levels which substantially increase central dopamine metabolism, markedly improved both psychiatric and choreic movements: both patients
Case 1 (C. A.)

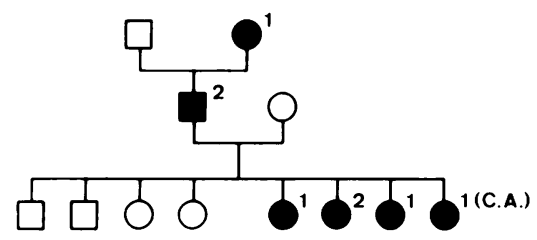

Black: Huntington's disease

White: Normal

1: Paranoid reaction

2: Depression

3: Chronic alcoholism

4: Catatonic-like picture
Case 2 (V.I.)

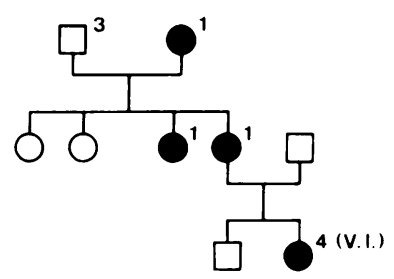

FIGURE The pedigrees of the two families.

TABLE 1

SUMMARY OF RELEVANT CLINICAL FINDINGS

\begin{tabular}{|c|c|c|c|c|c|c|c|}
\hline \multirow[b]{3}{*}{ Case } & \multirow[b]{3}{*}{ Sex } & \multirow[b]{3}{*}{$\begin{array}{l}A g c \\
(y r)\end{array}$} & \multirow[b]{3}{*}{$\begin{array}{c}\text { Psychiatric } \\
\text { onset }\end{array}$} & \multirow{3}{*}{$\begin{array}{c}\text { Illness } \\
\text { duration } \\
(y r)\end{array}$} & \multicolumn{3}{|c|}{ Clinical picture } \\
\hline & & & & & \multicolumn{2}{|c|}{ Severity of } & \multirow{2}{*}{$\begin{array}{c}\text { Wechsler-Bellevue } \\
\text { intellectual } \\
\text { impairment } \\
(\%)\end{array}$} \\
\hline & & & & & $\begin{array}{c}\text { Psychiatric } \\
\text { disturbances }\end{array}$ & $\begin{array}{c}\text { Choreic } \\
\text { movements }\end{array}$ & \\
\hline 1 & $\mathrm{~F}$ & 52 & Yes & 6 & $++t$ & $+t+$ & 76 \\
\hline 2 & $\mathrm{~F}$ & 42 & Yes & 5 & +++ & +++ & - \\
\hline
\end{tabular}


TABLE 2

CSF LEVELS OF MONOAMINE METABOLITES

\begin{tabular}{llrr}
\hline & & \multicolumn{2}{c}{ Case } \\
\cline { 3 - 4 } & CSF metabolites $(n g / m l)$ & 1 & 2 \\
HVA & Basal values & 10 & 10 \\
& After phenothiazine derivative therapy & 14 & 10 \\
\multirow{3}{*}{ MHPG } & After L-dopa therapy & 30 & 50 \\
& Basal values & 60 & 60 \\
& After phenothiazine derivative therapy & 15 & 90 \\
5-HIAA & After L-dopa therapy & 30 & 60 \\
& Basal values & 100 & 60 \\
& After phenothiazine derivative therapy & 130 & 10 \\
& After L-dopa therapy & 30 & 60 \\
\hline
\end{tabular}

were able to walk and feed without any help, the abnormal movements, especially those of the face, were markedly reduced, speech became almost fluent, and the two patients showed a marked improvement in behaviour, becoming less excitable and more controlled.

The L-dopa treatment brought about a marked increase in the level of CSF HVA in both patients, to three and five times respectively their previous values (Table 2).

\section{COMMENT}

Our two cases add to four other similar ones from the literature on Huntington's chorea (two cases of Tan et al. (1972) and two cases of Schenk and Leijnse-Ybema (1974).

We are fully aware that our method of measuring HVA and other metabolites, as Barbeau (1973) pointed out, only scratches the surface of Dopa metabolism. Nevertheless, we think that the existence of cases of the type described above-that is, which show, on the one hand, a great improvement of psychiatric symptoms and choreic movements after treatment with L-dopa and, on the other, a clear-cut decrease in CSF HVA basal values, followed by a marked increase after L-dopa therapy-deserves careful attention, in spite of the great individual variations in the values of MHPG and 5-HIAA, both in basal conditions and after therapy. In our cases, the HVA values did not show significant variations after phenothiazine treatment.

Disturbances of dopamine metabolism in Huntington's chorea may be related to decrease (Klawans, 1970) or increase in DA turnover
(Curzon et al., 1972; Bernheimer and Hornykiewicz, 1973; Chase, 1973), which, in turn, is dependent on the state of striatal DA receptors (Hornykiewicz, 1971).

There are good reasons to support the theory that the unbalanced dopaminergic relationship between the caudate nucleus and the putamen (Hornykiewicz, 1973) and/or the excessive stimulation of a damaged striatum by a relatively normal nigrostriatal DA pathway (Mardsen, 1975 ) could be the cause of choreic movements. Nevertheless, the fact that in our cases L-dopa proved to be effective in checking choreic movements cannot be accounted for by this theory and must simply be taken as evidence for the existence of a peculiar variety of the disease for which there is still no convincing pathophysiological explanation.

REFERENCES

Aquilonius, S. M., and Sjöström, R. (1971). Cholinergic and dopaminergic mechanisms in Huntington's chorea. Life Science, 10, 405-414.

Barbeau, A. (1969). L-Dopa therapy in Parkinson's disease. A critical review of nine years' experience. Canadian Medical Association Journal, 10, 791-800.

Barbeau, A. (1973). Biochemistry of Huntington's chorea. In Advances in Neurology, vol. 1, pp. 473-516. Edited by A. Barbeau, T. N. Chase, and G. W. Paulson. Raven Press: New York.

Barbeau, A., Mars, H., and Gillo-Joffroy, L. (1971). Adverse clinical side effects of Levodopa therapy. In Recent Advances in Parkinson's Disease, pp. 203-237. Edited by F. H. McDowell and C. H. Markham. Davis: Philadelphia.

Bernheimer, H., Birkmayer, W., and Hornykiewicz, O. (1966). Homovanillinsäure in liquor cerebrospinalis: Untersuchungen bei Parkinson-Syndrom und anderen Erkrankungen des Z.N.S. Wiener klinische Wochenschrift, 78, 417-419.

Bernheimer, H., Birkmayer, W., Hornykiewicz, O., Jellinger, K., and Seitelberger, F. (1973). Brain dopamine and the syndromes of Parkinson and Huntington. Clinical, morphological and neurochemical correlations. Journal of the Neurological Sciences, 20, 415-455.

Bernheimer, H., and Hornykiewicz, O. (1973). Brain amines in Huntington's chorea. In Advances in Neurology, vol. 1, pp. 525-531. Edited by A. Barbeau, T. N. Chase, and G. W. Paulson. Raven Press: New York.

Birkmayer, W. (1969). The importance of monoamine metabolism for the pathology of the extrapyramidal system. Journal of Neuro-visceral Relations, suppl. 9, 297-308. 
Chase, T. N. (1973). Biochemical and pharmacologic studies of monoamines in Huntington's chorea. In Advances in Neurology, vol. 1, pp. 533-542. Edited by A. Barbeau, T. N. Chase, and G. W. Paulson. Raven Press: New York.

Cotzias, G. C., Papavisiliou, P. S., and Gellene, R. (1969). Modification of Parkinsonism: chronic treatment with L-dopa. New England Journal of Medicine, 280, 337-345.

Curzon, G., Gumper, J., and Sharpe, D. (1972). Amine metabolites in the cerebrospinal fluid in Huntington's chorea. Journal of Neurology, Neurosurgery and Psychiatry, 35, 514-519.

Guilleminault, C., Tharp, B. R., and Cousin, D. (1973). HVA and 5-HIAA CSF measurement and 5-HTP, trials in some patients with involuntary movements. Journal of the Neurological Sciences, 18, 435-441.

Hornykiewicz, O. (1966). Dopamine (3-hydroxytryptamine) and brain function. Pharmacological Reviews, 18, 925-964.

Hornykiewicz, O. (1971). Histochemistry, biochemistry and pharmacology of brain catecholamines in extrapyramidal syndromes in man. In Monoamines Noyaux Gris Centraux et Syndrome de Parkinson, pp. 143-157. Edited by J. de Ajuriaguerra and G. Gautier. Masson: Paris.

Hornykiewicz, O. (1973). Metabolism of dopamine and L-dopa in human brain. In Frontiers in Catecholamine Research, pp. 1101-1107. Edited by E. Usdin and S. Snyder. Pergamon Press: New York.

Klawans, H. L. (1970). A pharmacologic analysis of Huntington's chorea. European Neurology, 4, 148-163.

Klawans, H. L. (1971). Cerebrospinal fluid homovanillic acid in Huntington's chorea. Journal of the Neurological Sciences, 13, 277-279.

Klawans, H. L., and Garvin, J. S. (1969). Preliminary observations on the treatment of Parkinsonism with L-dopa: a study of 105 patients. Diseases of the Nervous System, 30, 737-746.

Korf, J., Ottema, S., and Van der Veen, I. (1971a). Fluorometric determination of homovanillic acid in biological material after isolation on sephadex G-10. Analytical Biochemistry, 40, 187-191.

Korf, J., Van Praag, H. M., and Sebens, J. B. (1971b). Effect of intravenously administered probenecid in humans on the levels of 5-hydroxyindoleacetic acid, homovanillic acid and 3-methoxy-4-hydroxy-phenylglycol in cerebrospinal fluid. Biochemical Pharmacology, 20, 659-668.

Korf, J., and Volkemburgh-Sikkema, T. (1969). Fluorimetric determination of 5 HIAA on human urine and cerebrospinal fluid. Clinica Chimica Acta, 26, 301.

Lal, S., de la Vega, C. E., Garels, E., and Sourkes, T. L. (1973). Apomorphine, pimozide, L-dopa and the probenecid test in Huntington's chorea. Psychiatria, Neurologia, Neurochirurgia, 76, 113-117.

Loeb, C., Roccatagliata, G., Albano, C., La Medica, G., Abbruzzese, G., and Canini, S. Rilievi sul metabolismo liquorale delle amine biogene nella corea di Huntington. Schweizer Archiv für Neurologie, Neurochirurgie und Psychiatrie (in press).

Marsden, C. D. (1975). The neuropharmacology of abnormal involuntary movement disorders (The dyskinesias). In Modern Trends in Neurology-6, pp. 141-166. Edited by D. Williams. Butterworths: London.

Schenk, G., and Leijnse-Ybema, H. J. (1974). Huntington's chorea and Levodopa. Lancet, I, 364.

Tan, B. K., Leijnse-Ybema, H. I., and v.d. Brand, H. J. (1972). Levodopa in Huntington's chorea. Lancet, 1, 903. 